\title{
$\beta$-Catenin in Soft tissue Sarcomas: Expression is Related to Proliferative Activity in High-Grade Sarcomas
}

Cornelius Kuhnen, M.D., Peter Herter, Ph.D., Oliver Müller, Ph.D., Thomas Muehlberger, M.D., Larissa Krause, Heinz Homann, M.D., Hans Ulrich Steinau, M.D., Klaus-Michael Müller, M.D.

Institute for Pathology, Limb Tumor Registry, University Hospital Bergmannsheil, Bochum, Germany (CK, LK, K-MM), Max-Planck-Institute for Molecular Physiology, Dortmund, Germany (PH, OM), Department of Plastic and Hand Surgery-Burn Centre, Limb Tumor Registry, University Hospital Bergmannsheil, Bochum, Germany (TM, HH, HUS)

Besides its role in cell adhesion, $\beta$-catenin exerts a function as an oncoprotein. The aim of this study was the characterization of its expression, possible mutation, and the assessment of $\beta$-catenin as a prognostic indicator for soft tissue sarcomas. A total of 115 soft tissue sarcomas were analyzed using immunohistochemistry, immunogold-electron microscopy, and DNA analysis. Information from 56 patients was available for follow-up. A statistically significant correlation was found between intracellular distribution of $\beta$-catenin and the proliferative activity (MIB-1 expression) in high-grade sarcomas $(P=.0008)$. $\beta$-catenin was identified with intracytoplasmic and nuclear accumulation, showing additional membranous staining in sarcomas with epithelioid pattern. Ultrastructurally, a colocalization between $\beta$-catenin and nuclear heterochromatin was demonstrated. In 22 analyzed tumors, only one (yet undescribed) mutation of the $\beta$-catenin gene (C-A transversion) could be detected. Prognostic validity of the cellular expression of $\beta$-catenin, however, was not proven. Apart from its membranous function as an effective molecule for cell-adhesion in sarcomas with epithelioid pattern, $\beta$-catenin may act as an oncoprotein in sarcomas with intracytoplasmic and nuclear localization with binding to nuclear DNA. A previously discussed stimulation of cell proliferation caused by an increased $\beta$-catenin level can also be postulated for high-grade soft tissue sarcomas in correlation with the rate of proliferation. Mutations of the $\beta$-catenin gene are prob-

Copyright () 2000 by The United States and Canadian Academy of Pathology, Inc.

VOL. 13, NO. 9, P. 1005, 2000 Printed in the U.S.A

Date of acceptance: April 6, 2000

Address reprint requests to: Cornelius Kuhnen, M.D., Institute for Pathology, Limb Tumor Registry, University Hospital Bergmannsheil, Bürkle-dela-Camp-Platz 1, D- 44789 Bochum, Germany; e-mail: patho-bhl@ruhruni-bochum.de; fax: 49-234-3026671. ably of lesser importance for the accumulation of $\beta$-catenin in soft tissue sarcomas.

KEY WORDS: $\beta$-catenin, Immunohistochemistry, Mutation analysis, Soft tissue sarcoma. Mod Pathol 2000;13(9):1005-1013

$\beta$-catenin, a $92 \mathrm{kDa}$ protein, was originally identified as the crucial connecting link of the Cadherin/ Catenin complex. Localized at the cell membrane protein Cadherin, it effects cell adhesion by arranging the binding of $\alpha$-catenin to cytosolic filaments $(1-3)$. The continuous Cadherin-bound distribution of $\beta$-catenin is a characteristic of regular epithelia with intact cell adhesion $(4,5)$. A reduction of membranous E-Cadherin and $\beta$-catenin was described as a factor in the pathogenesis for invasive tumor cell units in carcinomas because a resulting loss of regular cell adhesion is seen as a promoting feature for tumor invasion (4-7). Another function of cytosolic $\beta$-catenin is the transduction of the wnt-signal $(3,8) . \beta$-catenin shows a high degree of homology (70\% amino acid sequence identity) to the Drosophila protein armadillo (3), which is a mediator of intracellular signal transduction. The relevance of $\beta$-catenin for the wnt-signaling pathway in conjunction with the APC-tumor suppressor protein was demonstrated and analyzed particularly in the carcinogenesis of colorectal tumors (9). Under physiologic conditions, the level of $\beta$-catenin is continuously reduced in the cytoplasm, as absent wnt-signals lead to complex formations between phosphorylated APC-protein and intracytoplasmic $\beta$-catenin, which results in its breakdown. Wntsignals or the mutation of APC genes, in contrast, effect the inactivation of the GSK-3- $\beta$ /APC complex and the synthesis of a functionally restricted APC protein. Therefore, $\beta$-catenin is not destabilized and can accumulate inside the cytoplasm (10-12). 


\begin{tabular}{|c|c|c|c|c|c|c|c|c|}
\hline \multirow{3}{*}{ Histologic Тype } & \multirow{3}{*}{$N$} & \multirow[b]{3}{*}{ Tumor Grade: } & \multicolumn{6}{|c|}{$\beta$-Catenin-Expression } \\
\hline & & & \multicolumn{3}{|c|}{ Low } & \multicolumn{3}{|c|}{ High } \\
\hline & & & I & II & III & I & II & III \\
\hline MFH & 22 & & 0 & 5 & 7 & 0 & 4 & 6 \\
\hline Myxofibrosarcoma & 22 & & 2 & 9 & 8 & 1 & 0 & 2 \\
\hline Liposarcoma & 15 & & 2 & 7 & 5 & 0 & 0 & 1 \\
\hline Synovial sarcoma & 10 & & 0 & 1 & 3 & 0 & 4 & 2 \\
\hline Epithelioid sarcoma & 2 & & 0 & 1 & 0 & 0 & 0 & 1 \\
\hline MPNST & 10 & & 1 & 2 & 1 & 2 & 0 & 4 \\
\hline Leiomyosarcoma & 6 & & 0 & 0 & 3 & 0 & 2 & 1 \\
\hline Rhabdomyosarcoma & 9 & & 0 & 2 & 4 & 0 & 1 & 2 \\
\hline ASPS & 5 & & 0 & 3 & 2 & 0 & 0 & 0 \\
\hline Others & 6 & & 0 & 0 & 4 & 0 & 0 & 2 \\
\hline Total & 115 & & 9 & 32 & 37 & 3 & 13 & 21 \\
\hline
\end{tabular}

MFH, malignant fibrous histiocytoma; MPNST, malignant peripheral nerve sheath tumor; ASPS, alveolar soft-part sarcoma.

Mutations of the APC gene, however, cannot only be shown in familial adenomatosis polyposis (FAP) patients, but also in the majority (60 to $80 \%)$ of sporadic colon carcinomas $(13,14)$.

Also, the mutation of the $\beta$-catenin gene itself can lead to a cellular accumulation of $\beta$-catenin, as the mutated $\beta$-catenin protein is not regulated by APC, in contrast to wild-type $\beta$-catenin (11). Mutations of the $\beta$-catenin gene were shown in colon carcinoma, melanoma, medulloblastoma, and prostate-, stomach-, and hepatocellular carcinomas $(11,15)$. $\beta$-catenin binds to transcription factors from the TCF/Lef group ( $\mathrm{T}$ cell-factor/lymphoid-enhancer factor) $(16,17)$. The complex of $\beta$-catenin and the transcription factor is transduced into the nucleus; this complex regulates particular target genes. $C$-myc was identified as the first target gene to be activated by $\beta$-catenin. Other genes or proteins, respectively, which are influenced by $\beta$-catenin in colorectal carcinomas include C-jun, fra-1, urokinase-type/plasminogen activator receptor (uPAR), and cyclin D1 $(14,15)$. The consequence of an accumulation of $\beta$-catenin and its respective target genes is the increased proliferation and/or inhibition of apoptosis representing the pivotal mechanisms of tumor initiation and progression $(14,15$, 18). Thus $\beta$-catenin is classified as an oncoprotein (18).

Soft tissue sarcomas constitute an array of heterogenous mesenchymal neoplasias for which a variety of oncogenes and proteins, tumor-suppressor genes, and growth factors have already been analyzed $(19,20)$. Expression and mutation of $\beta$-catenin and APC were described in aggressive fibromatosis, a subtype of mesenchymal tumors $(21,22)$. APC mutations in the fibromatoses of FAP syndromes and the loss of chromosome $5 \mathrm{q}$, the chromosomal localization of the APC gene in sporadic desmoid fibromatoses, indicate their relevance for the pathogenesis of fibromatoses as soft tissue tumors $(22,23)$. Yet the aim of this study was the characterization of $\beta$-catenin expression possible - mutation and a possible prognostic value in soft tissue sarcomas, i.e., in mesenchymal tumors other than fibromatoses.

\section{MATERIALS AND METHODS}

\section{Patients and Tissue Specimens}

One hundred fifteen soft tissue sarcomas of 93 patients were incorporated in this study, including 13 patients with recurrent tumors, from the limb tumor registry Bochum. All patients' tumors were resected between 1991 and 1998 in the department of Plastic and Reconstructive Surgery, University Hospital Bochum, Germany. The sex distribution was 62 males and 31 females. The age of the patients ranged from 21 to 85 years (median, 55.5). The primary therapy for all tumors consisted of operative resection with any eventual adjuvant chemotherapy and/or radiotherapy following afterwards. Informed consent was obtained from all patients who participated in this study. The sarcomas were predominantly localized in deep soft tissue of the upper extremity ( $n=27,24 \%$ ); lower extremity ( $n=76,66 \%)$; and head, neck, and trunk ( $n=12$, $10 \%)$. Intrathoracic and retroperitoneal tumors were excluded. Seventy-nine tumors (69\%) were localized in the proximal portion of the extremity and $36(31 \%)$ in distal parts. For prognostic significance, the sarcomas were divided into two groups according to size (24). Group one with up to $5 \mathrm{~cm}$ consisted of 42 cases (36.5\%), group two included 73 tumors $(63.5 \%)$ measuring more than $5 \mathrm{~cm}$. The diagnosis of different types of sarcomas was made using established diagnostic criteria (25-27). The distribution of individual diagnosis was as following: 22 pleomorphic sarcomas $(\mathrm{NOS}=$ not otherwise specified, so-called MFH), 22 myxofibrosarcomas ("myxoid" type of MFH), 15 liposarcomas (10 myxoid/round cell, three well differentiated/dedif- 
ferentiated, two pleomorphic), 10 MPNST (malignant peripheral nerve sheath tumor), 10 synovial sarcomas, two epithelioid sarcomas, 15 leiomyo/ rhabdomyosarcomas, five alveolar soft-part sarcomas, eight fibrosarcomas, and one each as extraskeletal osteosarcoma, extraskeletal myxoid chondrosarcoma, hemangiopericytoma, clear cell sarcoma, PNET, and spindle cell sarcoma NOS. For grading of soft tissue sarcomas, the so-called FNCLCC system (Fédération Nationale des Centers de Lutte Contre le Cancer) developed by the French Federation of Cancer Centers Sarcoma Group was used (28). This three-grade system is based on the evaluation of tumor differentiation, mitotic rate, and amount of tumor necrosis. Twelve cases were classified as G I (10.4\%), 45 cases as G II (39.1\%), and 58 cases as G III (50.5\%), accordingly. Due to the small number of cases in the G I group, all G I and G II sarcomas were jointly grouped as one class of low- to medium-grade malignancies as opposed to the high-grade group of G III sarcomas. Detailed data about the clinical course of disease were available for 56 patients. The median follow-up period for surviving patients was $18.5 \mathrm{mo}$, with a mean of $28.6 \mathrm{mo}$ and a range of 6 to $75 \mathrm{mo}$. Of the 56 patients, seven patients (12.5\%) received adjuvant postoperative chemotherapy. Twelve patients (21.4\%) received radiotherapy following the tumor resection. A combined radio/chemotherapy was applied in five cases $(8.9 \%)$. No data could be secured about the follow-up care of the remaining patients. Since no detailed information about the postoperative therapy was available in $57.2 \%$ of the patient group, we omitted the incorporation of further therapeutic means other than surgery for the statistical analysis.

\section{Immunohistochemistry}

Immunohistochemical analysis was performed using a monoclonal mouse anti-human antibody directed against $\beta$-catenin (Transduction Laboratories, Lexington, $\mathrm{KY}$ ) and monoclonal mouse anti-human antibody MIB-1 directed against the Ki-67-antigen (Dianova, Hamburg, Germany). Immunostaining was performed using the alkalinephosphatase-anti-alkaline phosphatase method (APAAP) (29). Four- $\mu \mathrm{m}$ sections were cut consecutively from formalin-fixed and paraffin-embedded tissue samples, mounted on poly-L-lysin coated slides and dried overnight at $37^{\circ} \mathrm{C}$. Paraffin sections were dewaxed by xylene, rehydrated with graded concentrations of ethanol, and finally washed in Tris-Buffer ( $\mathrm{pH}$ 7.2) for $10 \mathrm{~min}$. A microwave pretreatment was required for $15 \mathrm{~min}$ at $600 \mathrm{~W}$ using citrate buffer for $\beta$-catenin and EDTA-buffer $(\mathrm{pH}$ 8.0) for MIB-1. The following steps were finalized by an automated staining system, DAKO TechMate
500 (DAKO, Hamburg, Germany). Sections were incubated with the primary antibody solution for 25 min at room temperature, using a working dilution of the antibody 1: 300 for $\beta$-catenin and 1: 500 for MIB-1. Slides were rinsed once in buffer (Puffer Kit, DAKO). Immunoreaction was demonstrated with the DAKO ChemMate Detection Kit (APAAP, Mouse, Code No. K 5000, DAKO), according to the specifications of the manufacturer. Sections were incubated with the chromogen alkalinephosphatase-substrate (Neufuchsin, DAKO) for 20 min at room temperature. Finally, sections were counterstained by Mayer's-hematoxylin for $3 \mathrm{~min}$, dehydrated in graded ethanol, and coverslipped. Negative controls used all reagents except the primary antibody.

Selected cases especially of sarcomas showing epithelioid features (e.g., biphasic syonovialsarcoma) were chosen for immunofluorescence labeling which proved to be more sensitive to demonstrate a membranous staining of $\beta$-catenin. Labeling of paraffin sections for immunofluorescence microscopy was performed according to the previously published incubation protocol (38).

\section{Semiquantitative Assessment of Cytosolic/Nuclear $\beta$-Catenin-Immunostaining}

The results of the immunohistochemically obtained rates of expression were analyzed semiquantitatively. The number of positively marked tumor cells was graded as ranging from $0(=$ no positive cells), 1 ( $=$ up to $10 \%$ positive cells), 2 ( $=10$ to $50 \%$ positive cells) to 3 (more than $50 \%$ positive cells). The intensity was noted as I (faint) or II (strong). The combination of these immunohistochemical reaction patterns resulted in 7 possible scores: 0 , 1/I, 1/II, 2/I, 2/II, 3/I, and 3/II. The reaction scores 0 to $2 /$ I were classified as negative or low expression and $2 / \mathrm{II}$ to $3 / \mathrm{II}$ as high expression of $\beta$-catenin.

\section{Proliferative Activity (MIB-1)}

The Ki-67 antigen is closely associated with the cell cycle. It is being expressed in all active phases of the cycle, not, however, during the G 0-phase, which renders its significance as a marker of proliferation $(31,32)$. The development of the Ki-67equivalent monoclonal antibody MIB-1 allows the immunohistochemical staining of routinely processed, paraffin-embedded tissue (33). A semiquantitative score was used to evaluate the percentage of MIB-1 positive tumor cell nuclei, irrespective of the intensity of the nuclear reaction. This percentage was determined by counting individual fields (medium power, $\times 25$ ): MIB- 1 score $1=$ less than $10 \%$; $2=10$ to $25 \%$; $3=$ more than $25 \%$. This classification was used according to previous studies about 
proliferation in sarcomas, which determined the prognostic significance of $10 \%$ or more positive MIB-1 results $(31,34)$. So-called "hot-spot" areas consisting of nodular concentrations of MIB-1 positive cell nuclei were not considered, unless clearly more than three were found within the same field (31). A total of three different fields were evaluated, which were determined by systematic movement of predetermined distances of the slides.

\section{Immunogold-Electron Microscopy}

Three selected cases showing clearly detectable intracytoplasmic and nuclear $\beta$-catenin immunostaining by light microscopy were examined. Fixation: Pieces of tumors were fixed by immersion for 2 hours with $4 \%$ paraformaldehyde dissolved in 0.2 м HEPES buffer (pH 7.4).

\section{Dehydration and embedding}

For post-embedding immunogold-electron microscopy, the specimen were dehydrated in an ascending ethanol series and embedded in LR White resin (London Resin Company, London, UK). The resin was polymerized by heat (at $50^{\circ} \mathrm{C}$ ) for two days in a vacuum oven.

\section{Post embedding immunogold-labeling}

For immunogold-labeling, ultrathin sections on nickel grids were floated with section down on the surface of small drops of the following incubation solutions: (1) $50 \mathrm{~mm}$ Glycin in phosphate buffered saline (PBS) for 15 min to block free aldehyde sites; (2) $5 \%$ normal goat serum diluted in PBS containing additionally $0.5 \%$ bovine serum albumin (BSA) and $0.2 \%$ gelatin for 30 min to block unspecific binding sites; (3) overnight incubation with primary antibody against $\beta$-catenin (Dianova, Hamburg, Germany) diluted 1:20 in PBS containing additionally $0.5 \%$ BSA and $0.2 \%$ gelatin (PBG); (4) after several rinsing steps in PBG (10 times for $3 \mathrm{~min}$ ) incubation with the secondary antibody (10 $\mathrm{nm}$ gold coupled goat anti-mouse IgG, BRITISH BIO CELL, Cardiff, UK) for 1 hour; (5) after rinsing 10 times in PBG and five times in PBS postfixation with $2 \%$ glutaraldehyde in PBS for 15 min. Finally, the grids were rinsed shortly five times in PBS followed by five times in A.dest. before counterstaining with uranyl acetate for $20 \mathrm{~min}$. For control experiments the incubation with the primary antibody was omitted. The labeled sections were investigated with a Zeiss 902 transmission electron microscope.

\section{DNA-Analysis}

\section{DNA purification}

In 22 cases, tumor tissue was snap-frozen as soon as possible after surgical excision and stored in liquid nitrogen. Uninvolved surrounding normal tissue was also obtained for study and processed in an identical manner. Genomic DNA was purified using commercial reagents and protocols (Qiagen, Hilden, Germany). The yield of total DNA was determined spectrophotometrically. Preparations gave similar total yields of 5 to $20 \mu$ g genomic DNA out of $25 \mathrm{mg}$ tissue.

\section{Analysis of mutations in the $\beta$-catenin gene}

The $\beta$-catenin gene region from nucleotides 218 through 422 including the complete GSK3 $\beta$ phosphorylation consensus motif was amplified and sequenced according to described protocols (35). Reaction products were analyzed on an $\mathrm{ABI}$ automated sequencer. Polymerase chain reaction (PCR) and sequence analysis of mutated samples were repeated twice to exclude PCR errors.

\section{Statistical Analysis}

Statistical significance was evaluated using the Fisher's exact test and a logistic regression model including Wald-tests and Likelihood-tests with $P<$ .05 (36). For analysis of overall survival and diseasefree survival, the Kaplan-Meier method was used. To examine a possible influence of different parameters on these survival periods, the log-rank test was used $(30,37)$.

\section{RESULTS}

\section{Immunohistochemistry}

Results of the localization of $\beta$-catenin in epithelial tissues showed the continuous membranebound distribution of this protein in all registered epithelial cells. Squamous epithelial cells of the skin served as an endogenous control group. Membrane-bound reactions in endothelial cells were found especially at the sites of cell-cellcontacts with neighboring epithelium. In contrast, only slight focal reactions were found in cases of isolated mesenchymal cells (like fibroblasts). No intracytoplasmic or nuclear accumulation of $\beta$-catenin was detected in regular, nontumorous tissue. A heterogenous pattern of distribution concerning the extent and localization of $\beta$-catenin existed in the studied sarcomas. Membranous as well as intracytoplasmic and nuclear patterns of distribution were noted. These two categories of expression were analyzed semiquantitatively (Table $1)$.

1. Rudimentary focal membranous localization of $\beta$-catenin was found in several spindle cell sarcomas. A conspicuously continuous distribution pattern at the cell membrane was noted in sarcomas with mainly epithelioid 
structures; for example, epithelioid sarcoma, biphasic synovial sarcoma, epithelioid malignant nerve sheath tumor, and clear cell sarcoma (Fig. 1).

2. Intracytoplasmic accumulation of $\beta$-catenin with variable intensity of reaction was shown in all sarcomas irrespective of their degree of morphological differentiation (Fig. 2).

3. Nuclear localization was also found in numerous tumors of various degrees of differentiation (Sarcoma NOS, so-called MFH, synovial sarcoma, MPNST, myxofibrosarcoma). Purely nuclear localization without intracytoplasmic distribution of $\beta$-catenin (meaning solely nuclear accumulation) existed next to mixed nuclear and cytoplasmic reaction types (Figs. 2 and 3).

\section{Immunogold-Electron Microscopy}

In addition to the localization of $\beta$-catenin in the cytoplasm, particularly at the rough endoplasmic reticulum, a colocalization between $\beta$-catenin and nuclear heterochromatin could be detected on the ultrastructural level in all analyzed cases (Fig. 4).

\section{DNA Analysis}

Only one mutation of the $\beta$-catenin was found in 22 analyzed tumors. Figure 5 shows the results of the sequencing of the $\beta$-catenin gene region of DNA from this case: a pleomorphic sarcoma (MFH). Interestingly, the sequence shows a yet undescribed mutation. The C-A transversion in the sequence leads to an amino acid change from serine to tyrosine at position 37 . The serines in this gene region are phosphorylated by GSK-3- $\beta(10,11)$. The loss of one of these phosphorylation sites leads to the accumulation of cytosolic $\beta$-catenin, which was evident in this case, and to the activation of gene expression by the nuclear $\beta$-catenin/TCF 4 complex. Thus, the detected $\beta$-catenin gene mutation can be regarded as oncogenic relevant.

\section{Cytosolic/Nuclear Localization of $\beta$-Catenin and Correlation to Clinico-Pathologic Parameters}

No statistically significant correlation was found between the level of expression of $\beta$-catenin (low versus high) and the degree of malignancy ( $P=$ .4258), the tumor size, or the localization of tumor (proximal versus distal). The group of G I/G IIsarcomas showed a tendency toward an extended expression of $\beta$-catenin together with an increased MIB-1 score of proliferation, again, however, without reaching statistical significance $(P=.0888)$ (Tables 2 and 3 ). In G III sarcomas, in contrast, a statistically significant correlation existed between those two variables $(P=.0008)$. Data of the expres-

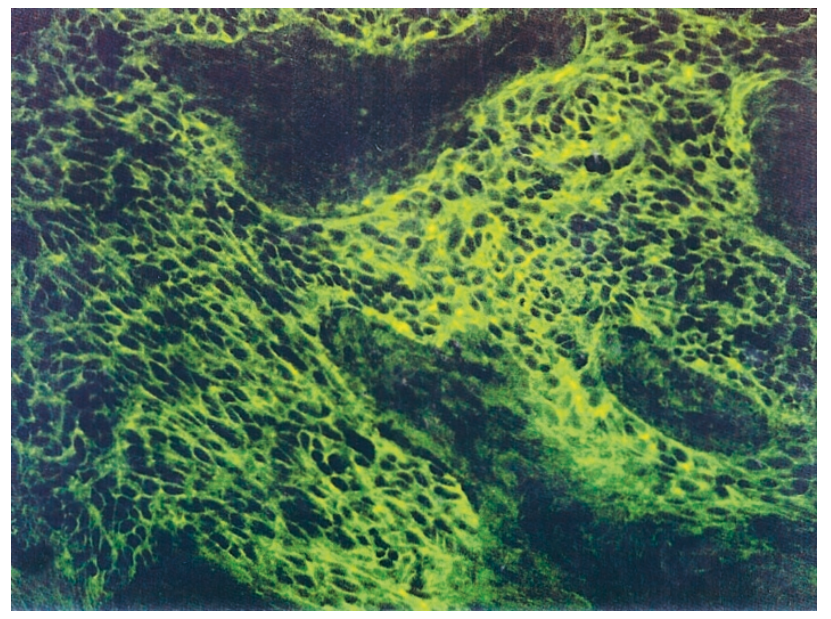

FIGURE 1. Immunohistochemistry for $\beta$-catenin in soft tissue sarcomas. Continuous membrane-bound $\beta$-catenin expression in the epithelioid component of a biphasic synovial sarcoma with the fibrous component showing only partial reaction (immunofluorescence; original magnification $250 \times$ ).

sion of $\beta$-catenin in 56 patients with clinical follow-up showed no statistically significant prognostic validity regarding the overall survival $(P=$ .3582) or the disease-free period of survival $(P=$ .818) (Fig. 6).

\section{DISCUSSION}

The role of $\beta$-catenin as an oncoprotein has been analyzed so far in a number of epithelial tumors, an increased expression was also shown in aggressive fibromatosis as a representative of mesenchymal tumors $(21,22)$.

The findings presented in this study substantiate the significance of $\beta$-catenin for soft tissue sarcomas as shown by the large intracytoplasmic and nuclear accumulation which accentuate its role as an oncoprotein, in addition to the $\beta$-cateninmediated membrane-bound cell adhesion. The "regular" function of $\beta$-catenin for cell adhesion was proved in sarcomas with epithelioid growth pattern. Considering hitherto existing findings of the effects of enhanced intracytoplasmic and nuclear expression of $\beta$-catenin in colon carcinomas and melanoma cell lines, in this present analysis (regarding the assessment of the oncogenic characteristics of $\beta$-catenin) only the intracytoplasmic/ nuclear localization was evaluated for a correlation to the rate of proliferation, as well as grading and the course of disease. Although an intracytoplasmic expression with in homogenous distribution was found in all types of sarcomas, an exclusively nuclear reaction was demonstrated only in some tumor cells. Our findings usually showed a combination of intracytoplasmic and, in comparison, a much stronger nuclear reaction. The combined intracytoplasmic and nuclear distribution in colon 


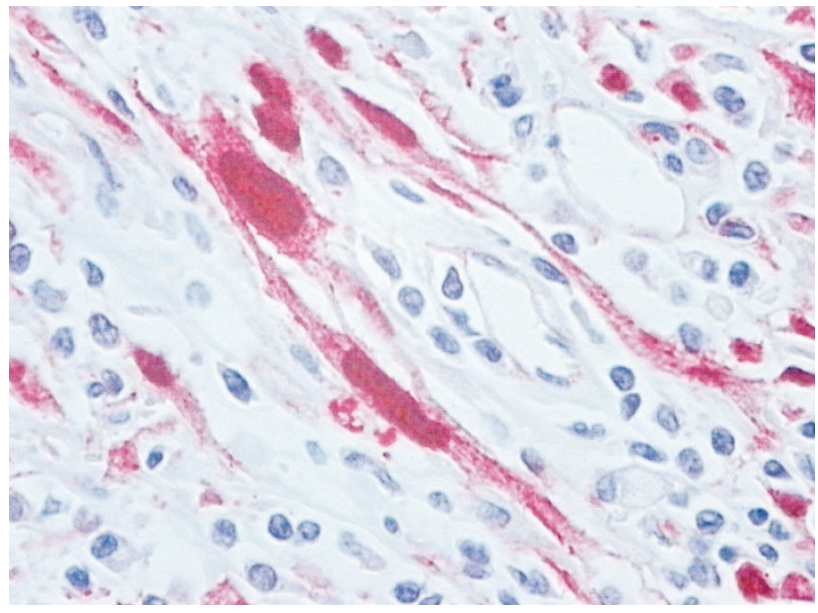

FIGURE 2. Immunohistochemistry for $\beta$-catenin in soft tissue sarcomas. Intracytoplasmic and nuclear accumulation of $\beta$-catenin in cells of a malignant peripheral nerve sheath tumor (original magnification, $40 \times$ ).

adenomas and carcinomas as epithelial neoplasms was described by several authors (38-40). Isolated nuclear localization was demonstrated particularly in the very early stages of colonic adenomas and could be a first morphologic indicator of the lost regulatory function of APC $(4,38)$. Because the exclusively membranous distribution of $\beta$-catenin is characteristic of regular epithelia $(4,5)$, a membranous localization combined with cytoplasmic and nuclear distribution is found in carcinomas $(7,41)$. Concerning localization of $\beta$-catenin in mesenchymal tissues, Kim et al. (42) reported a cytoplasmic distribution of $\beta$-catenin in fibroblasts without significant amounts at the cell surface. Nuclear $\beta$-catenin, however, was not detected in regular fibroblasts in contrast, for example, to fibroblastic appearing melanoma cells (42). Soler et al. (43) also described an important role of $\beta$-catenin in mesenchymal cells with increased proliferation of dermal fibroblast that overexpressed this protein. This observation is interesting regarding our own presented results with correlation of $\beta$-cateninexpression to proliferative activity in high-grade malignant mesenchymal tumors. In a previous study on fibromatoses by Tejpar et al. (44), cytoplasmic and nuclear staining for $\beta$-catenin was found in the mesenchymal tumor cells, comparable to the described immunohistochemical reaction patterns in our own series. In normal fibrocytes and endothelial cells, staining was restricted to cytoplasmic or membranous areas (44). These results are in good accordance with our own findings, showing only focal densities of $\beta$-catenin in nontumorous mesenchymal cells without nuclear accumulation. Taken together, $\beta$-catenin is not only restricted to epithelial tissue, but is also of importance for mesenchymal tissues.

The subcellular localization of $\beta$-catenin in the nuclei of sarcoma cells shown in this study by im-

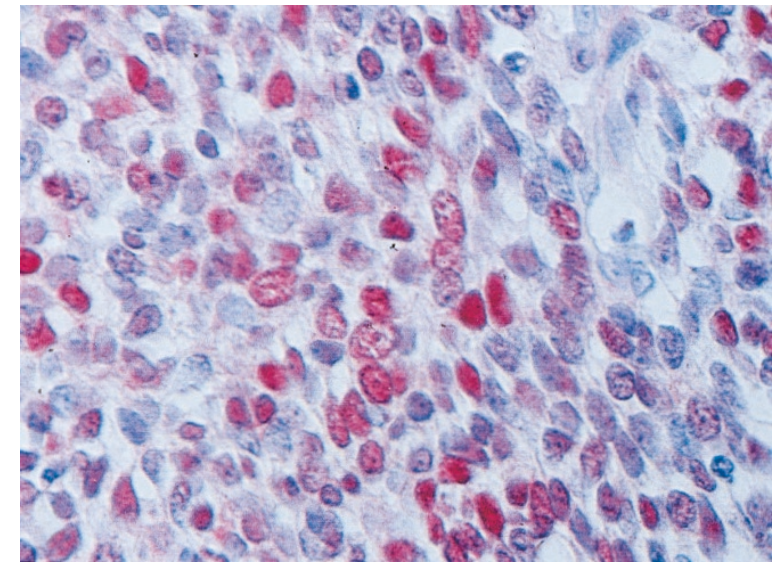

FIGURE 3. Immunohistochemistry for $\beta$-catenin in soft tissue sarcomas. Nuclear $\beta$-catenin expression in tumor cells of a monophasic synovial sarcoma (original magnification, $40 \times$ ).

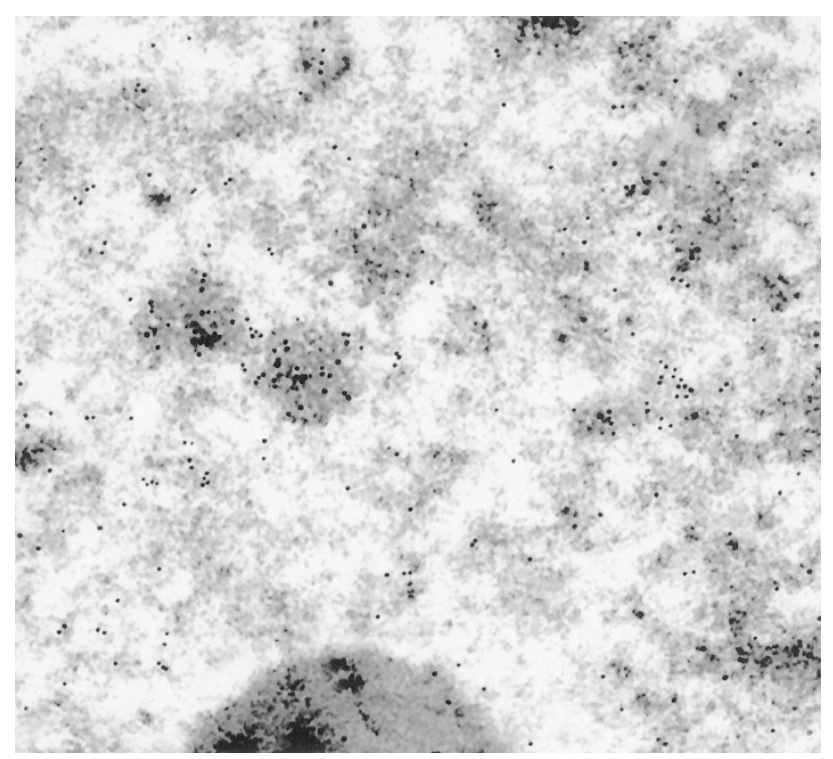

FIGURE 4. Immunogold-electron microscopy for $\beta$-catenin: association between $\beta$-catenin and nuclear heterochromatin. Bottom, part of nucleolus (pleomorphic sarcoma NOS: malignant fibrous histiocytoma; original magnification, 20,000×).

munohistochemical and ultrastructural findings suggests a function of $\beta$-catenin as an oncoprotein in sarcomas as well. The oncoprotein forms complexes with nuclear transcription factors of the TCF/Lef group, which, following transduction into the nucleus, bind DNA $(16,17)$. The accumulation of $\beta$-catenin triggers the activation of target genes (e.g., C-myc, cyclin D1), which results in an accelerated proliferation of cells. This is seen as one of the crucial mechanisms for tumor initiation and progression and was described in detail in colorectal carcinogenesis $(14,15,18)$. The present statistically significant correlation between expression of $\beta$-catenin and the rate of proliferation (using the monoclonal antibody MIB-1) in high-grade (G III) sarcomas further corroborates this relevance of $\beta$-catenin for soft tissue sarcomas. These results 


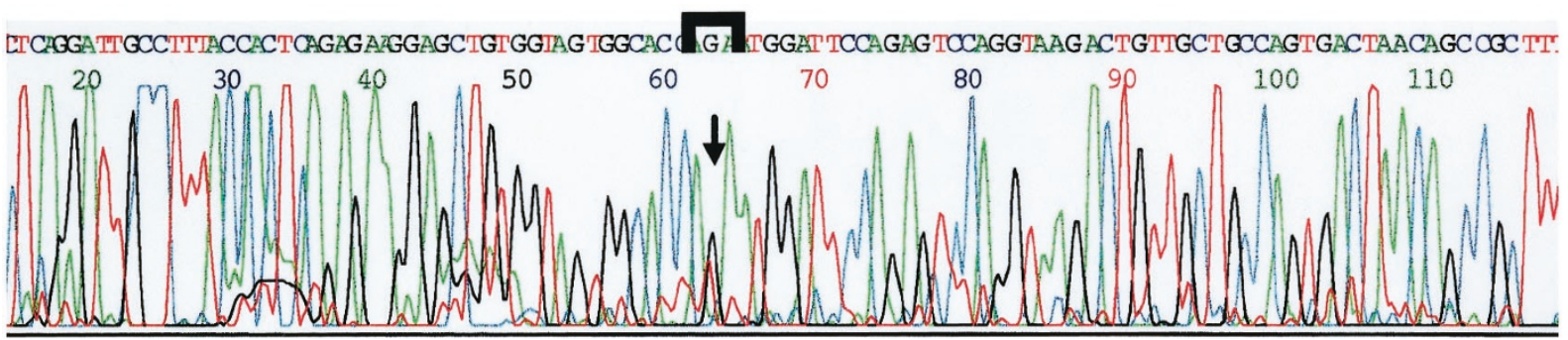

FIGURE 5. Sequencing results of a pleomorphic sarcoma NOS (malignant fibrous histiocytoma). The reverse $\beta$-catenin sequence from bp 256 to bp 357 (codon 19 to codon 53) is shown in $3^{\prime}-5^{\prime}$ direction. The heterozygous transversion in codon 37 is indicated by an arrow.

highlight the effect of $\beta$-catenin on the progression of sarcomas as a function of the oncogenic potency of this protein on the proliferation of cells.

Mutations of the $\beta$-catenin gene have already been described for several, predominantly epithelial tumors in various frequency (45-49). The mutation analyses in this study showed only one case of a yet undescribed $\beta$-catenin gene mutation out of 22 sarcomas. Since the mutation is at a position that is necessary for the regulation of the $\beta$-catenin turnover, its immunostaining in the same tumor may be the direct consequence of this oncogenic mutation. Our results are in accordance with find- ings in melanomas reported by Rimm et al. (50), who also found a frequent intracytoplasmic/nuclear accumulation of $\beta$-catenin, but with concurrent mutations of the respective gene in only one of 65 tumors. Overall, mutations of the $\beta$-catenin gene can be considered rare events in soft tissue sarcomas in contrast to findings concerning endometrial $(41,45)$ or hepatocellular tumors $(47,51)$. Hence, an intracytoplasmic and nuclear accumulation of $\beta$-catenin and the subsequent activation of target genes in sarcomas is more likely the consequence of a dysfunction in the regulatory mechanism of the wnt-signal transduction pathway rather than the

TABLE 2. $\beta$-Catenin- and MIB-1-Expression in 58 High-Grade Sarcomas

\begin{tabular}{|c|c|c|c|c|c|c|c|c|}
\hline \multirow{3}{*}{ Histologic Type } & \multirow{3}{*}{$N$} & \multirow[b]{3}{*}{ MIB Score: } & \multicolumn{6}{|c|}{$\beta$-Catenin-Expression } \\
\hline & & & \multicolumn{3}{|c|}{ Low } & \multicolumn{3}{|c|}{ High } \\
\hline & & & 1 & 2 & 3 & 1 & 2 & 3 \\
\hline MFH & 13 & & 0 & 4 & 3 & 0 & 2 & 4 \\
\hline Myxofibrosarcoma & 10 & & 4 & 4 & 0 & 0 & 0 & 2 \\
\hline Liposarcoma & 6 & & 2 & 3 & 0 & 1 & 0 & 0 \\
\hline Synovial sarcoma & 5 & & 0 & 3 & 0 & 1 & 1 & 0 \\
\hline Epithelioid sarcoma & 1 & & 0 & 0 & 0 & 1 & 0 & 0 \\
\hline MPNST & 5 & & 0 & 0 & 1 & 0 & 0 & 4 \\
\hline Leiomyosarcoma & 4 & & 1 & 2 & 0 & 0 & 1 & 0 \\
\hline Rhabdomyosarcoma & 6 & & 0 & 3 & 1 & 0 & 1 & 1 \\
\hline ASPS & 2 & & 1 & 1 & 0 & 0 & 0 & 0 \\
\hline Others & 6 & & 3 & 1 & 0 & 0 & 0 & 2 \\
\hline Total & 58 & & 11 & 21 & 5 & 3 & 5 & 13 \\
\hline
\end{tabular}

MFH, malignant fibrous histiocytoma; MPNST, malignant peripheral nerve sheath tumor; ASPS, alveolar soft-part sarcoma.

TABLE 3. $\beta$-Catenin- and MIB-1-Expression in 115 Soft Tissue Sarcomas

\begin{tabular}{|c|c|c|c|c|c|c|c|c|}
\hline \multirow{3}{*}{ Histologic Type } & \multirow{3}{*}{$N$} & \multirow[b]{3}{*}{ MIB Score: } & \multicolumn{6}{|c|}{$\beta$-Catenin-Expression } \\
\hline & & & \multicolumn{3}{|c|}{ Low } & \multicolumn{3}{|c|}{ High } \\
\hline & & & 1 & 2 & 3 & 1 & 2 & 3 \\
\hline MFH & 22 & & 1 & 7 & 4 & 0 & 6 & 4 \\
\hline Myxofibrosarcoma & 22 & & 12 & 6 & 1 & 0 & 1 & 2 \\
\hline Liposarcoma & 15 & & 10 & 3 & 1 & 1 & 0 & 0 \\
\hline Synovial sarcoma & 10 & & 0 & 4 & 0 & 3 & 2 & 1 \\
\hline Epithelioid sarcoma & 2 & & 0 & 1 & 0 & 1 & 0 & 0 \\
\hline MPNST & 10 & & 2 & 1 & 1 & 2 & 0 & 4 \\
\hline Leiomyosarcoma & 6 & & 1 & 2 & 0 & 1 & 2 & 0 \\
\hline Rhabdomyosarcoma & 9 & & 0 & 5 & 1 & 0 & 2 & 1 \\
\hline ASPS & 5 & & 3 & 2 & 0 & 0 & 0 & 0 \\
\hline Others & 6 & & 3 & 1 & 0 & 0 & 0 & 2 \\
\hline Total & 115 & & 38 & 32 & 8 & 9 & 14 & 14 \\
\hline
\end{tabular}

MFH, malignant fibrous histiocytoma; MPNST, malignant peripheral nerve sheath tumor; ASPS, alveolar soft-part sarcoma. 


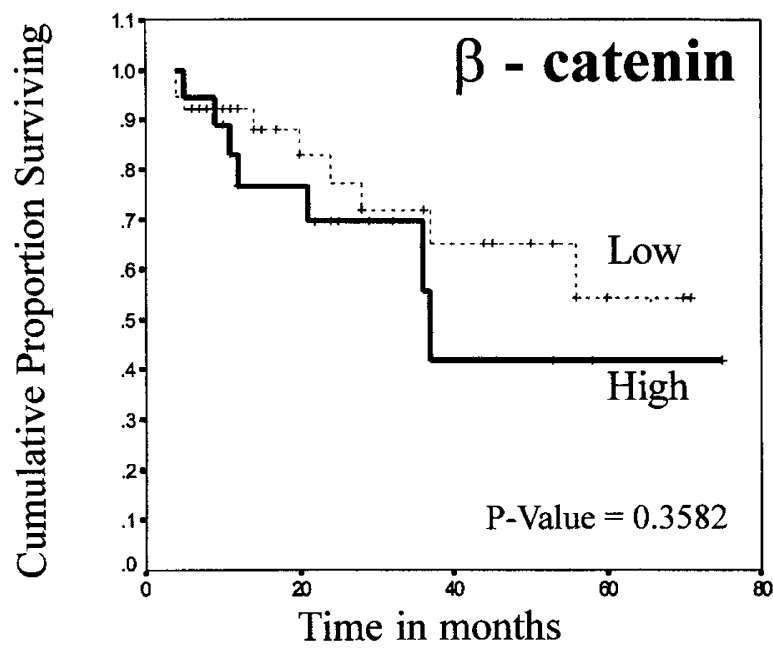

FIGURE 6. Kaplan-Meier overall survival curves in 56 patients with soft tissue sarcomas according to low versus high $\beta$-catenin-expression.

effect of a $\beta$-catenin protein stabilized through mutation. APC mutation in sarcomas is presumably the main cause for the demonstrated accumulation of $\beta$-catenin. This, however, warrants further investigations in the future.

The prognostic relevance of (membrane-bound) $\beta$-catenin was previously discussed in particular for cell adhesion. Defects in the Cadherin/Cateninmediated cell-cell-interaction can lead to an enhancement of invasive growth. For instance, a deterioration in the course of disease was noted in bladder tumors with a simultaneously reduced expression of $\beta$-catenin (6). Also, in non-small cell lung tumors, a worse prognosis was correlated with decreased expression of $\beta$-catenin (52). An association between reduced expression of $\beta$-catenin and a higher degree of tumor malignancy was proved in esophageal carcinomas, yet no prognostic significance could be deducted from that (7). Gunther et al. (53) found no prognostic validity regarding the nuclear expression of $\beta$-catenin in their studies on rectal carcinomas. Neither did our studies of 56 patients with soft tissue sarcomas show any prognostic relevance of the distribution of intracellular $\beta$-catenin. Since the present analysis includes only a moderate follow-up period (median, 18.5 mo) only restricted assessments should be made. Final conclusions about the prognostic validity of intracellular expression of $\beta$-catenin are presently not possible. Further studies with more extensive follow-up periods in patients with soft tissue sarcomas will be necessary to obtain concise answers to those questions.

Acknowledgments: The authors gratefully acknowledge the excellent technical assistance of Susanne Schaub (Institute for Pathology, University Hospital Bergmannsheil, Bochum, Germany) and Alice
Kasprzynski (Max-Planck-Institute for molecular physiology, Dortmund, Germany).

\section{REFERENCES}

1. Polakis P. The adenomatous polyposis coli (APC) tumor suppressor. Biochemica et Biophysica Acta 1997;1332:F12747.

2. Vermeulen S, Van Marck V, Van Hoorde L, Van Roy F, Bracke M, Mareel M. Regulation of the invasion suppressor function of the cadherin/catenin complex. Path Res Pract 1996;192: 694-707.

3. Gumbiner BM. Signal transduction by $\beta$-catenin. Curr Op Cell Biol 1995;7:634-40.

4. Valizadeh A, Karayiannakis AJ, El-Hariry I, Kmiot W, Pignatelli M. Expression of E-cadherin-associated molecules $(\alpha-, \quad \beta-, \gamma$-catenins and p120) in colorectal polyps. Am J Pathol 1997;150:1977-83.

5. Takayama T, Shiozaki H, Shibamoto S, Oka H, Kimura Y, Tamura $\mathrm{S}$, et al. $\beta$-catenin expression in human cancers. Am J Pathol 1996;148:39-46.

6. Shimazui T, Schalken JA, Giroldi LA, Jansen CFJ, Akaza H, Koiso K, et al. Prognostic value of cadherin-associated molecules $\left(\alpha-, \beta-, \gamma\right.$-catenins and p120 $\left.{ }^{\text {cas }}\right)$ in bladder tumors. Cancer Res 1996;56:4154-8.

7. Nakanishi Y, Ochiai A, Akimoto S, Kato H, Watanabe H, Tachimori Y, et al. Expression of E-cadherin, $\alpha$-catenin, $\beta$-catenin and plakoglobin in esophageal carcinomas and its prognostic significance. Oncology 1997;54:158-65.

8. Funayama N, Fagotto F, McCrea P, Gumbiner BM. Embryonic axis induction by the Armadillo repeat domain of $\beta$-catenin: evidence for intracellular signaling. J Cell Biol 1995;128:959-68.

9. Su LK, Vogelstein B, Kinzler KW. Association of the APC tumor suppressor protein with catenins. Science 1993;262: $1734-7$.

10. Morin PJ, Sparks AB, Korinek V, Barker N, Clevers H, Vogelstein $\mathrm{B}$, et al. Activation of $\beta$-catenin-Tcf signaling in colon cancer by mutations in $\beta$-catenin or APC. Science 1997;275:1787-90.

11. Rubinfeld B, Robbins P, El-Gamil M, Albert I, Porfiri E, Polakis $\mathrm{P}$. Stabilization of $\beta$-catenin by genetic defects in melanoma cell lines. Science 1997;275:1790-2.

12. Munemitsu S, Albert I, Souza B, Rubinfeld B, Polakis P. Regulation of intracellular $\beta$-catenin levels by the adenomatous polyposis coli (APC) tumor-suppressor protein. Proc Natl Acad Sci U S A 1995;92:3046-50.

13. Gumbiner BM. Carcinogenesis. A balance between $\beta$-catenin and APC. Curr Biol 1997;7:R443-6.

14. Mann B, Gelos M, Siedow A, Hanski ML, Gratchev A, Ilyas M, et al. Target genes of $\beta$-catenin-T cell-factor/lymphoidenhancer-factor signaling in human colorectal carcinomas. Proc Natl Acad Sci U S A 1999;96:1603-8.

15. Tetsu O, McCormick F. $\beta$-Catenin regulates expression of cyclin D1 in colon carcinoma cells. Nature 1999;398:422-6.

16. Behrens J, von Kries JP, Kühl M, Bruhn L, Wedlich D, Grosschedl R, et al. Functional interaction of $\beta$-catenin with the transcription factor LEF-1. Nature 1996;382:638-42.

17. Aoki M, Hecht A, Kruse U, Kemler R, Vogt PK. Nuclear endpoint of Wnt signaling: neoplasmic transformation induced by transactivating lymphoid-enhancing factor 1. Proc Natl Acad Sci U S A 1999;96:139-44.

18. Peifer M. $\beta$-catenin as oncogene: the smoking gun. Science 1997;275:1752-5.

19. Duda RB, Cundiff D, August CZ, Wagman LD, Bauer KD. Growth factor receptor and related oncogene determination in mesenchymal tumors. Cancer 1993;71:3526-30.

20. Reissmann PT, Simon MA, Lee WH, Slamon DJ. Studies of 
the retinoblastoma gene in human sarcomas. Oncogene 1989;4:839-43.

21. Li C, Bapat B, Alman BA. Adenomatous polyposis coli gene mutation alters proliferation through its $\beta$-cateninregulatory function in aggressive fibromatosis (desmoid tumor). Am J Pathol 1998;153:709-14.

22. Alman BA, Li C, Pajerski ME, Diaz-Cano S, Wolfe HJ. Increased $\beta$-catenin protein and somatic APC mutations in sporadic aggressive fibromatoses (desmoid tumors). Am J Pathol 1997;151:329-34.

23. Hasegawa SL, Fletcher CDM. Fibromatosis in the adult. Adv Pathol 1996;9:259-75.

24. Mandard AM, Petiot JF, Marnay J, Mandard JC, Chasle J, De Ranieri E, et al. Prognostic factors in soft tissue sarcomas. Cancer 1989;63:1437-51.

25. Enzinger FM, Weiss SW. Soft tissue tumors. 3rd ed. St. Louis, MO: Mosby; 1995.

26. Mentzel T, Calonje E, Wadden C, Camplejohn RS, Beham A, Smith MA, et al. Myxofibrosarcoma. Clinicopathologic analysis of 75 cases with emphasis on the low-grade variant. Am J Surg Pathol 1996;20:391-405.

27. Weiss SW. Histological typing of soft tissue tumours, 2nd ed. New York: Springer-Verlag; 1994.

28. Guillou L, Coindre JM, Bonichon F, Binh Bui N, Terrier P, Collin $\mathrm{P}$, et al. Comparative study of the National Cancer Institute and French Federation of Cancer Centers Sarcoma Group grading systems in a population of 410 adult patients with soft tissue sarcoma. J Clin Oncol 1997;15:350-62.

29. Cordell JL, Falini B, Erber WN. Immunoenzymatic labeling of monoclonal antibodies using immune complexes of alkaline phosphatase and monoclonal antialkaline phosphatase (APAAP) complexes. J Histochem Cytochem 1984;32:219-29.

30. Parmar MKB, Machin D. Survival analysis. 1st ed. Chichester: Wiley; 1995.

31. Choong PFM, Akerman M, Willen H, Andersson C, Gustafson $\mathrm{P}$, Baldetorp B, et al. Prognostic value of Ki-67 expression in 182 soft tissue sarcomas: proliferation-a marker of metastasis? APMIS 1994;102:915-24.

32. Jensen V, Høyer M, Sørensen FB, Keller J, Jensen OM. MIB-1 expression and iododeoxyuridine labelling in soft tissue sarcomas: an immunohistochemical study including correlations with p53, bcl-2 and histological characteristics. Histopathology 1996;28:437-44.

33. Jensen V, Sørensen FB, Bentzen SM, Ladekarl M, Nilesen OS, Keller J, et al. Proliferative activity (MIB-1 index) is an independent prognostic parameter in patients with high-grade soft tissue sarcomas of subtypes other than malignant fibrous histiocytomas: a retrospective immunohistological study including 216 soft tissue sarcomas. Histopathology 1998;32:536-46.

34. Choong PFM, Akerman M, Willén H, Andersson C, Gustafson P, Alvegard TA, Rydholm A. Expression of proliferating cell nuclear antigen (PCNA) and Ki-67 in soft tissue sarcoma. Is prognostic significance histotype-specific? APMIS 1995; 103: 797-805.

35. Müller O, Nimmrich I, Finke U, Friedl W, Hoffmann I. A $\beta$-catenin mutation in a sporadic colorectal tumor of the RER phenotype and absence of $\beta$-catenin germline mutations in FAP patients. Genes Chromosomes Cancer 1998;22: $37-41$.
36. Kleinbaum DG. Logistic regression. 1st ed. New York: Springer-Verlag; 1994.

37. Collett D. Modelling survival data in medical research. 1st ed. London: Chapman \& Hall; 1994.

38. Herter P, Kuhnen C, Müller KM, Wittinghofer A, Müller O. Intracellular distribution of $\beta$-catenin in colorectal adenomas, carcinomas and Peutz-Jeghers polyps. J Cancer Res Clin Oncol 1999;125:297-304.

39. Brabletz T, Jung T, Hermann K, Günther K, Hohenberger W, Kirchner T. Nuclear overexpression of the oncoprotein $\beta$-Catenin in colorectal cancer is localized predominantly at the invasion front. Path Res Pract 1998;194:701-4.

40. Inomata M, Ochiai A, Akimoto S, Kitano S, Hirohashi S. Alteration of $\beta$-catenin expression in colonic epithelial cells of familial adenomatous polyposis patients. Cancer Res 1996;56:2213-7.

41. Gamallo C, Palacios J, Moreno G, Calvo de Mora J, Suarez A, Armas A. $\beta$-catenin expression pattern in stage I and II ovarian carcinomas. Am J Pathol 1999;155:527-36.

42. Kim K, Daniels KJ, Hay ED. Tissue-specific expression of $\beta$-catenin in normal mesenchyme and uveal melanomas and its effect on invasiveness. Exp Cell Res 1998;245:79-90.

43. Soler C, Grangeasse C, Baggetto LG, Damour O. Dermal fibroblast proliferation is improved by $\beta$-catenin overexpression and inhibited by E-cadherin expression. FEBS Letters 1999;442:178-82.

44. Tejpar S, Nollet F, Li C, Wunder JS, Michils G, dal Cin P, et al. Predominance of $\beta$-catenin mutations and $\beta$-catenin dysregulation in sporadic aggressive fibromatosis (desmoid tumor). Oncogene 1999;18:6615-20.

45. Fukuchi T, Sakamoto M, Tsuda H, Maruyama K, Nozawa S, Hirohashi S. $\beta$-catenin mutation in carcinoma of the uterine endometrium. Cancer Res 1998;58:3526-8.

46. de La Coste A, Romagnolo B, Billuart P, Renard CA, Buendia MA, Soubrane O, et al. Somatic mutations of the $\beta$-catenin gene are frequent in mouse and human hepatocellular carcinomas. Proc Natl Acad Sci U S A 1998;95:8847-51.

47. Voeller HJ, Truica CI, Gelmann EP. $\beta$-catenin mutations in human prostate cancer. Cancer Res 1998;58:2520-3.

48. Palacios J, Gamallo C. Mutations in the $\beta$-catenin gene (CTNNB1) in endometrioid ovarian carcinomas. Cancer Res 1998;58:1344-7.

49. Zurawel RH, Chiappa SA, Allen C, Raffel C. Sporadic medulloblastomas contain oncogenic $\beta$-catenin mutations. Cancer Res 1998;58:896-9.

50. Rimm DL, Caca K, Hu G, Harrison FB, Fearon ER. Frequent nuclear/cytoplasmic localization of $\beta$-catenin without exon 3 mutations in malignant melanoma. Am J Pathol 1999;154: 325-9.

51. Koch A, Denkhaus D, Albrecht S, Leuschner I, von Schweinitz D, Pietsch T. Childhood hepatoblastomas frequently carry a mutated degradation targeting box of the $\beta$-catenin gene. Cancer Res 1999;59:269-73.

52. Retera JM, Leers MP, Sulzer MA, Theunissen PH. The expression of $\beta$-catenin in non-small-cell lung cancer: a clinicopathological study. J Clin Pathol 1998;51:891-4.

53. Gunther K, Brabletz T, Kraus C, Dworak O, Reymond MA, Jung A. Predictive value of nuclear $\beta$-catenin expression for the occurrence of distant metastases in rectal cancer. Dis Colon Rectum 1998;41:1256-61. 